\title{
Programa de Atenção Integral à Saúde da Mulher: uma análise institucional
}

\section{Integral Health Care Women's Program: an institutional analysis}

Yasmine Mansur

Pontifícia Universidade Católica de Minas Gerais (PUC/MG)

E-mail: yasmine.mansur@gmail.com

Adélia Marina de Campos Cursino

Pontifícia Universidade Católica de Minas Gerais (PUC/MG)

E-mail: marinacursino18@ hotmail.com

Armindo dos Santos de Souza Teodósio

Pontifícia Universidade Católica de Minas Gerais (PUC/MG)

E-mail: armindo.teodosio@gmail.com

Resumo: $\mathrm{O}$ artigo analisa a influência do movimento feminista na construção do PAISM (Programa de Atenção Integral à Saúde da Mulher), uma das principais políticas públicas voltadas às questões de gênero no Brasil, utilizando para tanto os marcos referenciais da teoria institucional. A fundamentação teórica do trabalho reside no chamado novo institucionalismo, entendido como uma importante perspectiva interpretativa, na medida em que destaca os aspectos simbólicos da produção e reprodução de políticas implementadas pelas organizações, para compreensão dos avanços, revezes e conquistas do movimento feminista em torno dos direitos de saúde da mulher. Trata-se de uma investigação de natureza qualitativa, baseada no acesso a fontes de dados secundários sobre o PAISM. Os resultados da análise indicam que os avanços do movimento feminista, tanto no âmbito internacional quanto nacional, somados ao contexto de redemocratização, resultaram em decisiva influência da sociedade civil na configuração de políticas de saúde voltadas às mulheres, buscando não apenas garantir melhores formas de acesso à saúde, mas também ampliar a compreensão da sociedade brasileira sobre as relações de gênero na contemporaneidade. A discussão a partir dos fundamentos do novo institucionalismo permitiu incorporar atores não governamentais e movimentos da sociedade civil na análise de políticas públicas, postura tão cara ao campo da gestão social.

Palavras-Chave: Políticas Públicas de Saúde; gênero; institucionalismo; movimento feminista.

Abstract: The article analyses the influence of the feminist movement in the construction of PAISM, one of the main public policies to gender issues in Brazil, using both benchmarks of institutional theory. The theoretical basis of the work lies in the so-called new institutionalism, 
MANSUR, Yasmine; CURSINO, Adélia Marina de Campos; TEODÓSIO, Armindo dos Santos de Souza. Programa de Atenção Integral à Saúde da Mulher: uma análise institucional

understood as an important interpretive perspective, in that it highlights the symbolic aspects of production and reproduction policies implemented by organizations to understand the advances, setbacks and achievements of the feminist movement around the health rights of women. This is an investigation of a qualitative nature, based on access to secondary data sources on the PAISM. The results of the analysis indicate that the advances of the feminist movement, both in the international and national levels, in addition to the re-democratization context, resulted in decisive influence of civil society in health policy configuration geared to women, seeking not only ensure better ways to access health, but also broaden the understanding of Brazilian society about gender relations in contemporary times. The discussion from the foundations of the new institutionalism allowed to incorporate nongovernmental actors and civil society movements in public policy analysis, posture so dear to the field of social management.

Keywords: Health Public Policy; gender; institutionalism; feminist movement.

\section{Introdução}

A intenção deste artigo é demonstrar como a teoria institucional pode servir como ferramenta analítica e metodológica para entender a influência do movimento feminista na idealização do PAISM. Por objetivar uma investigação sobre os direitos da mulher refletidos no PAISM, cabe aqui compreender o que significa ser mulher. Nesse sentido, os estudos feministas buscam entender as relações sociais estabelecidas entre homens e mulheres, essa relação de poder, que tem sua gênese na própria constituição das sociedades.

O movimento feminista chama atenção para as atividades empreendidas pelas mulheres sobretudo no âmbito da coletividade para assegurar a manutenção e a provisão dos recursos de consumo coletivo. Nesse sentido, vários são os enfoques que trazem e associam a mulher no desenvolvimento de políticas públicas, de todos eles o que nos interessa é o empoderamento dessas mulheres que anseiam e dirigem movimentos em prol do seu reconhecimento com o ator fundamental na sociedade. Ampliando a noção de que os indivíduos detêm o controle sobre suas vidas no contexto da participação, visando as transformações da realidade, social e política, em que vivem (Wallerstein, 1994).

Para compreensão deste fenômeno, entendemos que a teoria institucional se baseia na forma como as regras e os procedimentos são incorporados pelas organizações, em busca de legitimidade, para tanto os mecanismos coercitivos, normativos e miméticos conformam a ação

Revista Brasileira de Políticas Públicas e Internacionais, v.4, n.1, julho/2019, pp. 29-47. 
MANSUR, Yasmine; CURSINO, Adélia Marina de Campos; TEODÓSIO, Armindo dos Santos de Souza. Programa de Atenção Integral à Saúde da Mulher: uma análise institucional

organizacional. Como exemplo dessa dinâmica pode-se observar o comportamento similar das estruturas nos hospitais, escolas, corpos de polícia e bombeiros (Hjort-Madsen, 2007).

Especificamente na vertente do novo institucionalismo, o Estado, não se submete simplesmente aos anseios da sociedade, sejam das classes ou dos grupos de interesse. As ações do Estado, implementadas por seus funcionários, obedecem à lógica de buscar reproduzir o controle de suas instituições sobre a sociedade, reforçando sua autoridade, seu poder político e sua capacidade de ação e controle sobre o ambiente que o circunda (Selzinck, 1996).

Em suma, as instituições possuem várias funções. Dentre elas está a redução de incertezas, introdução de regularidade e estabilidade. Embora seja importante considerar as estruturas formais das instituições estatais e sociais, entender como a configuração institucional estabelecida, modela as instituições políticas, se torna importante (Cavalcante,2011). Assim, este artigo discute como os movimentos feministas influenciaram a concepção de políticas públicas para mulheres, através do o Programa de Atenção Integral à Saúde da Mulher (PAISM). Para tanto, utiliza os referenciais da teoria institucional e do novo institucionalismo e recorre à consulta de fontes de dados secundários para fundamentar uma análise em bases qualitativas dessa política pública.

\section{Aspectos do institucionalismo como marco norteador de políticas públicas}

Além de uma perspectiva da ciência política, a teoria institucional está preocupada com a estrutura organizacional e o comportamento nas organizações públicas. O institucionalismo distingue-se de outros paradigmas intelectuais, especialmente pelas ortodoxias do individualismo metodológico, ao apontar para a necessidade de compreender a ação dos indivíduos e suas manifestações coletivas, as mediações entre estruturas sociais e comportamentos individuais. Essas mediações são precisamente as instituições (Selznick, 1996).

Para Scott (1987), a sabedoria implícita na abordagem da Teoria Institucional é a de reconhecer, desde o início, que não existe uma, mas diversas variantes. Já Berger e Luckmann (2008) argumentam que a realidade é socialmente constituída: fatos, necessidades, cobranças lapidam a realidade das pessoas de acordo com suas funções. Assim aquilo que acreditamos ser

Revista Brasileira de Políticas Públicas e Internacionais, v.4, n.1, julho/2019, pp. 29-47. 
MANSUR, Yasmine; CURSINO, Adélia Marina de Campos; TEODÓSIO, Armindo dos Santos de Souza. Programa de Atenção Integral à Saúde da Mulher: uma análise institucional

a realidade é socialmente construído, ou seja, a institucionalização é a repetição de ações que ganham significados e valores (Berger \& Luckmann, 2008).

A teoria institucional trata as instituições como dadas pelo ambiente, e a institucionalização como um estado qualitativo, isto é, dado arranjo estrutural está ou não institucionalizado na organização. Assim a teoria institucional entende que elementos de natureza mais ampla configuram as ações de indivíduos, grupos e organizações em um determinado contexto, considerando uma lógica sugerida pelas instituições dominantes naquele campo (Machado-Da-Silva; Gonçalves, 1998; Fonseca, 2003). Assim essa interpretação, “a institucionalização aparece tanto como processo quanto como variável-atributo" (Tolbert \& Zucker, 1998, p.196).

Diferentemente das teorias racionais, a teoria institucional não analisa com profundidade a dinâmica interna da mudança organizacional, mas contribui fortemente para explicar as similaridades e a estabilidade de arranjos organizacionais em uma área de interesse - o setor público. Assim, a Teoria Institucional, expressa a governança das organizações sob o ponto de vista intraorganizacional e infraorganizacional (Fonseca, 2003; Carvalho, Goulart \& Vieira, 1999; Dimaggio \& Powell, 2005; Scott, 2001).

No modo intraorganizacional, a teoria institucional preconiza que os mitos do ambiente institucional impõem práticas e procedimentos que muitas vezes dificultam a eficiência das ações, a realização de mudanças e a incorporação de evoluções tecnológicas. Muitas vezes repetindo comportamentos, que se tornam o único modo aceitável de proceder, ações como estas são explicadas pelo isomorfismo mimético (Fonseca, 2003; Carvalho, Goulart \& Vieira, 1999; Dimaggio \& Powell, 2005; Scott, 2001).

Sob o ponto de vista infraorganizacional, a teoria institucional estabelece que a busca pela legitimidade das ações e decisões, frente às incertezas e restrições, leva à homogeneidade em estrutura, cultura e resultados, fazendo com que as organizações do setor público se tornem similares, sem necessariamente serem mais eficientes. A incorporação de elementos institucionalizados proporciona uma salvaguarda para as decisões e atividades, protegendo o gestor público de ter sua conduta questionada. A decisão se torna legitima, sendo utilizada pelo gestor para reforçar o seu apoio e assegurar a sua sobrevivência. Desse modo, as estratégias,

Revista Brasileira de Políticas Públicas e Internacionais, v.4, n.1, julho/2019, pp. 29-47. 
MANSUR, Yasmine; CURSINO, Adélia Marina de Campos; TEODÓSIO, Armindo dos Santos de Souza. Programa de Atenção Integral à Saúde da Mulher: uma análise institucional

mesmo que sejam razoáveis para uma organização, podem não ser racionais. Assim, o simples fato de serem sancionadas normativamente, a probabilidade da sua adoção aumenta (Fonseca, 2003; Carvalho, Goulart \& Vieira, 1999; Dimaggio \& Powell, 2005; Scott, 2001).

Carvalho, Goulart \& Vieira (1999), DiMaggio \& Powell (2005) e Scott (2001) discutem as formas de isomorfismo. Para eles, o isomorfismo se dá através de três formas: coercitivo, mimético e regulativo. Cada um deles valoriza ou se orienta na condução e compreensão da ação de tornar as organizações semelhantes em busca de legitimidade. Para Meyer \& Rowan (1977), nesse processo de isomorfismo as organizações incorporam elementos que são externamente legitimados, procurando imprimir rótulos a suas atividades mobilizando o comprometimento dos participantes internos e dos constituintes externos.

$\mathrm{O}$ isomorfismo institucional, acredita que os processos tornam as organizações mais similares sem necessariamente torna-las mais eficientes (Dimaggio \& Powell, 2005), pode ser considerado o conceito que melhor representa esse processo de homogeneização, decorrente da busca pela legitimidade, é assim, importante ferramenta para se entender as políticas e o cerimonial inerente às organizações do setor público, e apresenta três mecanismos por meio dos quais as mudanças isomórficas institucionais ocorrem:

- Isomorfismo Coercitivo: Se dá a partir da coerção. Ela pode originar-se tanto das organizações dentro do campo em que atua, ou de instituições como o governo. Como exemplo podemos citar a atuação do governo no que diz respeito a edição de normas gerais para aquele campo organizacional e o seu descumprimento pode gerar situações extremamente penosas para aquelas organizações que não se enquadrem nestes modelos (Carvalho, Goulart \& Vieira, 1999; Dimaggio \& Powell, 2005).

- Isomorfismo Mimético: O isomorfismo mimético ocorre pela reprodução de determinados modelos e estruturas organizacionais que foram considerados bemsucedidos. Na medida em que uma determinada indústria é percebida como tendo resultados acima da média das demais indústrias, há uma tendência de se "copiar" aquele modelo (Carvalho, Goulart \& Vieira, 1999; Dimaggio \& Powell, 2005).

- Isomorfismo normativo: Se refere ao conjunto de normas adotados principalmente para regulação das profissões Ele encontra-se normalmente associado a reprodução de

Revista Brasileira de Políticas Públicas e Internacionais, v.4, n.1, julho/2019, pp. 29-47. 
MANSUR, Yasmine; CURSINO, Adélia Marina de Campos; TEODÓSIO, Armindo dos Santos de Souza. Programa de Atenção Integral à Saúde da Mulher: uma análise institucional

comportamentos em determinadas categorias profissionais específicas, na medida em que profissionais de mesma área tendem a ter comportamentos similares (Carvalho, Goulart \& Vieira, 1999; Dimaggio \& Powell, 2005).

Em suma, podemos entender que a vida institucional é organizada, através de um conjunto de papéis, procedimentos, memórias e identidades compartilhadas e previamente dadas (Cavalcante, 2011).

\subsection{O Novo Institucionalismo: uma dimensão central para a análise política}

A vertente do Novo Institucionalismo surgiu e se consolidou como abordagem específica da ciência política nos anos 1970 e 1980, pretendia ser uma resposta, por um lado, à suposta crise de paradigmas que colocava em cheque abordagens como o funcionalismo, o behaviorismo e o marxismo, por outro lado, como resposta ao desafio proposto pela emergência de abordagens racionalistas e formalistas, como a teoria da escolha racional e a teoria dos jogos, que negavam os fundamentos sociológicos e históricos nos quais as abordagens tradicionais se apoiavam para explicar a ação social. O Novo Institucionalismo é, uma tentativa de resgate do processo de construção institucional como fundamento teórico e empírico da ação social. Ao mesmo tempo em que é uma tentativa ainda que incipiente, de unificação das ciências sociais em torno do paradigma institucional que a priori não rejeita nenhum dos paradigmas anteriores, mas procura reelaborá-los dentro de uma concepção que opere a mediação entre as grandes teorias sociais e a análise empírica, especialmente na vertente comparativa (Selznick,1996; Prates 2000).

No decorrer das duas últimas décadas surgiram as mais diversas tentativas de abordagem institucionalista, não necessariamente contraditórias, mas cuja heterogeneidade tem dificultado a configuração do espaço (teórico e empírico) de diálogo entre suas diferentes variantes:

a. A primeira incorpora alguns argumentos da abordagem da escolha racional para explicar o surgimento e o papel das instituições; O institucionalismo da escolha racional enfatiza o caráter instrumental e estratégico do comportamento dos indivíduos, afirma que as instituições reduzem a incerteza em relação à ação dos outros, na medida em que oferecem uma certeza

Revista Brasileira de Políticas Públicas e Internacionais, v.4, n.1, julho/2019, pp. 29-47. 
MANSUR, Yasmine; CURSINO, Adélia Marina de Campos; TEODÓSIO, Armindo dos Santos de Souza. Programa de Atenção Integral à Saúde da Mulher: uma análise institucional

razoável quanto ao comportamento presente e vindouro dos atores. Neste caso, as instituições são o resultado intencional e funcional da estratégia de otimização de ganhos e redução de custos de transação, por parte dos agentes. A permanência da instituição resulta do fato de ela oferecer mais benefícios aos atores interessados do que as formas institucionais concorrentes (Selznick,1996; Prates 2000).

b. A segunda tem sua origem na sociologia organizacional, entende que os contextos institucionalizados (organizações, rotinas, normas de ação) são capazes de gerar a ação coletiva. O institucionalismo sociológico apresenta um enfoque cultural, ao mesmo tempo em que enfatiza a dimensão rotineira do comportamento e o papel da visão de mundo do ator na interpretação das situações. Ou seja, o comportamento jamais é plenamente estratégico ou calculado. A instituição corresponde aos sistemas simbólicos, esquemas cognitivos e modelos morais sobre os quais é baseada a interpretação e a ação dos sujeitos, e sua manutenção ou mudança depende do grau de legitimidade que lhe é conferido pelo ambiente cultural (Selznick, 1996; Prates, 2000).

c. A última se vincula à ampla linhagem de abordagens histórico-estruturais (marxista, funcionalista, weberiana) e procura reelaborar os fundamentos sociológicos e históricos da ação coletiva produzidos por essas abordagens (interesses, ideologias, tradições e estruturas organizacionais) como forças sociais e históricas que configuram contextos institucionais que impedem, retardam, consolidam ou aceleram processos de mudança social (Selznick, 1996; Prates, 2000).

Os principais críticos do novo institucionalismo alegam que seus autores falham na tentativa de tornar totalmente endógenas as instituições no modelo de desenvolvimento econômico. Argumentando que o modelo neoclássico apresenta quatro categorias de variáveis exógenas (preferências, tecnologias, dotações e regras), e não três; e que o programa contém ambiguidades quando tenta explicitar como as instituições respondem às mudanças dos parâmetros exógenos. Tais críticas discordam que as instituições são pontos de partida de mudanças no processo histórico, apresentando padrões de desenvolvimento moldados pelo ambiente dado exogenamente. Outra crítica diz respeito ao entendimento do comportamento

Revista Brasileira de Políticas Públicas e Internacionais, v.4, n.1, julho/2019, pp. 29-47. 
MANSUR, Yasmine; CURSINO, Adélia Marina de Campos; TEODÓSIO, Armindo dos Santos de Souza. Programa de Atenção Integral à Saúde da Mulher: uma análise institucional

humano, ao observarem que a obediência às regras não pode ser explicada exclusivamente por meio de princípios utilitaristas (Selznick, 1996; Prates, 2000; Hall \& Taylor, 2003).

No entanto, o novo institucionalismo avança no estudo da importância das instituições para os aspectos econômicos e políticos. Seus teóricos buscam desenvolver um modelo de análise econômica, política e social, cuja premissa é adotar as instituições como variáveis explicativas do desenvolvimento econômico e do processo histórico. Nesse sentido, possibilita uma análise holística em que diversos atores podem ter influência sob uma determinada mudança. Sendo assim, essa abordagem viabiliza a proposta deste trabalho uma vez que, mesmo tendo um papel secundário o movimento feminista influenciou o processo em que o Estado é o principal ator (Selznick, 1996; Prates, 2000; Hall \& Taylor, 2003). Entendemos que cada uma dessas vertentes apresenta princípios que auxiliam na analise das questões centrais trazidas pelos processos de descentralização de políticas que culminaram no PAISM.

Diante desse perfil teórico, o novo institucionalismo permite algumas considerações que possibilitam uma análise ampla das políticas públicas, incluindo as de saúde. As regras de uma organização subjacentes ao processo de produção de políticas públicas, por exemplo, afetam e são afetadas pelo poder de decisão dos atores. No caso das políticas públicas de saúde, elas podem ser condicionadas por regras institucionais ligadas ao governo, à estrutura do Estado, ou por dinâmicas sociais ligadas principalmente à ação no âmbito da sociedade civil, no qual se destacam os movimentos sociais.

Na trajetória de várias políticas públicas nas sociedades contemporâneas, inclusive no caso brasileiro, o papel dos diferentes movimentos que lutam pelos direitos da mulher tem destaque. Essa realidade problematiza a trajetória das lutas por direitos por parte dos movimentos feministas e sua incidência na configuração de políticas públicas. Esse realidade parece ganhar mais vulto no campo das políticas públicas de saúde, arena na qual se manifestam tensões, embates, convergências e ameaças aos direitos da mulher, seja pela reprodução de práticas cotidianas de opressão que fragilizam a saúde das mulheres, seja pelas controvérsias que temas como os direitos reprodutivos despertam no seio da sociedade. Para compreendermos melhor o papel da mulher na sociedade e a luta e conquista de direitos, na seção seguinte traremos ao debate questões sobre o movimento feminista.

Revista Brasileira de Políticas Públicas e Internacionais, v.4, n.1, julho/2019, pp. 29-47. 
MANSUR, Yasmine; CURSINO, Adélia Marina de Campos; TEODÓSIO, Armindo dos Santos de Souza. Programa de Atenção Integral à Saúde da Mulher: uma análise institucional

\section{Da luta à conquista de direitos}

Ao longo da História da humanidade, sempre existiram mulheres que se revoltaram contra a opressão masculina e lutaram por liberdade, muitas pagando, inclusive, com a própria vida (Pinto, 2010). No entanto, como movimento social de luta coletiva, ocorrendo de certa forma simultaneamente em vários países, esta revolta tomou corpo com o feminismo.

A luta feminista surge a partir do reconhecimento das mulheres como oprimidas, na certeza de que as relações entre homens e mulheres podem ser transformadas politicamente, uma vez que não estão inscritas na natureza. Os movimentos feministas diferem-se dos movimentos populares de mulheres, uma vez que estes últimos não expõem frontalmente a exigência de direitos específicos para as mulheres (Fougeyrollas - Schwebel, 2009). São diferentes por proporem uma nova articulação, por trazerem a mulher da esfera privada para a esfera pública, por tornar a mulher visível na sociedade (Oliveira, Gaio \& Bonacim, 2009).

Apenas na segunda metade do século XX é que se manifesta o feminismo como movimento coletivo de luta das mulheres ocidentais. Essas lutas surgem a partir do reconhecimento das mulheres como oprimidas, na certeza de que as relações entre homens e mulheres podem ser transformadas politicamente (Fougeyrollas - Schwebel, 2009).

As mulheres, conquistaram um mundo de possibilidades e oportunidades até então inimagináveis. Elas foram à luta, mostraram que são capazes, buscaram seu lugar em segmentos até então exclusivamente masculinos, inclusive no mundo dos negócios. Porém, apenas neste século e em um número reduzido de sociedades, é que as barreiras e sanções institucionais e estruturais relacionadas às mulheres começaram a cair (Bruschini 2007; Descarries, 2000; Pinto, 2010). O objetivo central do feminismo era a transformação da mulher na sociedade, superando a desigualdade existente nas relações entre homens e mulheres (Farah, 2004).

Duas ondas históricas de movimentos feministas foram distinguidas por historiadores e feministas na América do Norte e na Europa. A primeira na segunda metade do século XIX e

início do século XX, com foco no direito ao voto. A segunda denominada de neofeminismo, acontece na metade dos anos 1960 e início dos anos 1970, não se fundamenta apenas na

Revista Brasileira de Políticas Públicas e Internacionais, v.4, n.1, julho/2019, pp. 29-47. 
MANSUR, Yasmine; CURSINO, Adélia Marina de Campos; TEODÓSIO, Armindo dos Santos de Souza. Programa de Atenção Integral à Saúde da Mulher: uma análise institucional

igualdade, mas no reconhecimento social de fundar essa igualdade dentro de um sistema patriarcal. Esta separação, é hoje descartada, uma vez que dá mostras de uma historiografia lacunar (Fougeyrollas - Schwebel, 2009).

Alguns autores diferenciam, ainda, os movimentos feministas em três correntes de pensamento: Feminismo Igualitário ou Universalista, Feminismo Radical e o Feminismo da Feminitude. A primeira delas, o Feminismo Igualitário ou Universalista, liderou o ressurgimento do movimento feminista, baseado na igualdade, fomentando a adoção de uma "questão das mulheres". O denominado Feminismo Radical é a segunda corrente. Este se baseia nos termos do homem dominante e da mulher dominada para realizar uma leitura feminista das relações sociais de sexo. Nos anos 1970, esta corrente ocupa grande parte do espaço teórico. A terceira corrente é o Feminismo da Feminitude, que aparecerá na década de 1980 se desenvolvendo paralelamente às diferentes tendências dos feminismos Igualitário e Radical, buscando revalorizar o território e o imaginário feminino, dando uma dimensão privada à vida da mulher (Descarries, 2000).

Se é indiscutível a importância deste movimento social, por outro lado a opressão feminina, não cessou com a conquista dos direitos iguais. O alcance da consciência individual e coletiva de homens e mulheres sobre a sua situação real é a maior de todas as batalhas do movimento feminista no mundo de hoje. Com o movimento feminista percebemos que a história e a cultura estão em constante mutação (Amorim, 2011).

Um exemplo dessa mutação é o código civil brasileiro que, em 1830, previa como legítimo o assassinato de mulheres adúlteras sem punição para o cônjuge. Em 1916 essa disposição foi alterada considerando o adultério razão de desquite. A constituição de 1969 ainda apresentava características machistas, porém na de 1988 algumas conquistas foram alcançadas, dentre elas: a mulher passa a ser igual ao homem perante a lei (Pedro \& Guedes, 2010).

Para a busca da igualdade entre os gêneros, os órgãos governamentais, como por exemplo as delegacias especializadas para mulheres, e os planos de políticas públicas para mulheres são entendidos como espaços políticos conquistados pelos movimentos feministas. Mesmo com a existência desses aparatos governamentais, no entanto, ainda persiste o desafio

Revista Brasileira de Políticas Públicas e Internacionais, v.4, n.1, julho/2019, pp. 29-47. 
MANSUR, Yasmine; CURSINO, Adélia Marina de Campos; TEODÓSIO, Armindo dos Santos de Souza. Programa de Atenção Integral à Saúde da Mulher: uma análise institucional

de garantir todos os direitos humanos às mulheres, o que demonstra que as demandas feministas não se findam na transformação do Estado (Miranda, 2009).

As pesquisas sobre a relação entre homens e mulheres evoluíram no sentido de que se passou a estudar a relação social, deixando de lado os atributos que distinguem as mulheres dos homens. A análise passou a se ocupar de gênero como construção social e da aquisição de masculinidade e feminilidade, separando-se do estudo, o sexo, como variável independente (Juteau, 2009).

Compreender os sentidos dos papéis sexuais nas diferentes épocas e sociedades e, como eles foram implementados, é o objetivo dos estudos de gênero (Chies, 2010). O conceito de gênero é uma conquista do movimento feminista e sua construção e afirmação é um grande avanço (Pedro \& Guedes, 2010). Corroborando com esta ideia, Descarries (2000) descreve os estudos feministas como procedimentos sociológicos e metodológicos para instituir as mulheres enquanto categoria social e o sexo e o gênero como categorias de análise, assim como para desconstruir as representações e os mecanismos reconstitutivos da divisão social dos sexos e de outros sistemas de dominação.

As mulheres, a quem antes cabia apenas o espaço doméstico, conquistam cada vez mais postos de trabalho dentro das organizações. Inseridas e economicamente ativas, as mulheres passaram a enfrentar o dilema da carreira versus vida familiar e afetiva e também, o dilema das relações sociais ainda marcadas por relações de gênero (Bruschini 2007; Vilas Boas, et al 2003; Oliveira, et al 2009).

A presença da mulher no mercado de trabalho e a sua contribuição para a produção econômica constituem desvios em relação aos papéis masculino, do pai provedor de renda e encarregado das relações da família com a sociedade, e feminino, da esposa e mãe que se consagra à vida doméstica e à função afetiva no âmbito familiar (Devreux, 2009). Diante este panorama teórico, que apresentou tanto as perspectivas institucionalista quanto questões ligadas ao movimento feminista, na seção seguinte, analisaremos o PAISM, sob à luz das abordagens anteriormente citadas.

Revista Brasileira de Políticas Públicas e Internacionais, v.4, n.1, julho/2019, pp. 29-47. 
MANSUR, Yasmine; CURSINO, Adélia Marina de Campos; TEODÓSIO, Armindo dos Santos de Souza. Programa de Atenção Integral à Saúde da Mulher: uma análise institucional

\section{O PAISM à luz do institucionalismo}

O Programa de Assistência Integral à Saúde da Mulher foi concebido em 1983 e destacou-se por ter sido o primeiro programa estatal a implantar a nível nacional o planejamento familiar ao mesmo tempo em que se tornou referência para a área de saúde pública incorporando princípios defendidos pelo movimento da reforma sanitária e novas concepções sobre a saúde da mulher, apregoadas pelo movimento feminista. Desde então, a atenção do governo federal à saúde da mulher deixou de ser vista unicamente através da relação materno-infantil, deu-se ênfase também as doenças ginecológicas prevalentes, prevenção e tratamento de doenças sexualmente transmissíveis (DST) e Aids. Além de assistência às mulheres vítimas de violência. O PAISM é uma organização das práticas de saúde que teve, desde seu início a intenção de trabalhar as questões do cotidiano da vida social para além das patologias, com uma proposta de saúde integral (Fonseca Sobrinho, 1993; Costa, 1999; Mesquita, 2011).

No entanto, foi a partir das pressões populares exercida por meio dos movimentos sociais, resultando na constituição de 1988, que traduziu a demanda pela descentralização dos serviços públicos básicos, através da cooperação e coordenação intergovernamental em que cada política requer uma estratégia de implementação, pautadas em adesão, barganhas e estratégias de indução (Arretche, 2004; Cavalcante, 2011),levou-nos a definir novos pressupostos para a gestão pública. Ainda que timidamente, esse processo de descentralização viabilizou espaços para serem trabalhadas as demandas e compromissos dos cidadãos, ampliando os espaços de participação através dos conselhos de políticas públicas e dos orçamentos participativos (Fleury, 1999; Andrade, 2006; Milani, 2008).

A partir de perspectivas políticas distintas, se produziu um grande consenso em torno da descentralização. A intenção seria de reafirmar a democracia, uma vez que as diversas formas de descentralização, poderia tornar os serviços públicos mais próximos do cidadão beneficiário ou usuário da política e também e por consequência mais eficientes, elevando os níveis reais de bem-estar da população. A descentralização à medida que dota de efetivo poder as instituições locais, possibilitaria um incentivo à participação política, uma vez que viabiliza formas mais efetivas de controle sobre a agenda e sobre as ações de governo (Arretche, 1996).

Revista Brasileira de Políticas Públicas e Internacionais, v.4, n.1, julho/2019, pp. 29-47. 
MANSUR, Yasmine; CURSINO, Adélia Marina de Campos; TEODÓSIO, Armindo dos Santos de Souza. Programa de Atenção Integral à Saúde da Mulher: uma análise institucional

Em 2008, a preocupação com a saúde da mulher ganhou força com a implantação do II Plano Nacional de Políticas para as Mulheres (II PNPM), responsável por aprofundar a atuação do governo na promoção de políticas de igualdade e justiça social com a inclusão de novos eixos estratégicos. A participação das mulheres nos espaços de poder e decisão; desenvolvimento sustentável no meio rural, na cidade e na floresta, com garantia de justiça ambiental, inclusão social, soberania e segurança alimentar; e direito à terra, moradia digna e infraestrutura social nos meios rural e urbano, todas essas manifestações sofrem claramente influência dos movimentos sociais, dentre eles o feminista, como fora dito anteriormente (Costa, 1999; Mesquita, 2011).

Os movimentos sociais são uma forma de participação, e constituem-se como "ações sociais coletivas de caráter sócio-político e cultural que viabilizam distintas formas da população se organizar e expressar suas demandas" (Gohn, 2003, p. 13). Assim, no contexto em que o PAISM foi implementado, qual seja, o de ampliação do conflito de interesses e do embate político-eleitoral durante o processo de redemocratização do país. Temos que os grupos que mediavam a relação entre o Estado e a sociedade civil no Brasil, o movimento da reforma sanitária e o movimento feminista, atuavam principalmente dentro do aparelho estatal e propunha mudanças no modelo de saúde pública brasileiro. O movimento feminista como o movimento da reforma sanitária, compartilhavam valores e características e foram igualmente marcados pelo embate constante entre uma posição autônoma em relação ao Estado e a busca por direitos e voz dentro do aparelho estatal (Escorel 1998; Costa, 1999; Mesquita, 2011).

Desta feita, o Programa de Assistência Integral à Saúde da Mulher (PAISM), em articulação com o papel dos atores envolvidos em sua elaboração -movimento sanitarista, Estado e movimento feminista - e com o quadro histórico, institucional e político do Brasil naquele momento, constituiu-se como uma proposta de política pública que incorporava novos e velhos paradigmas da saúde da mulher. Acreditamos, portanto, que as concepções feministas sobre a saúde da mulher influenciaram a formulação de uma política pública universalista, na qual as ações destinadas para as mulheres baseavam-se na substituição do conceito de saúde materno-infantil pelo conceito mais abrangente de saúde integral da mulher, contido no PAISM (Escorel, 1998; Costa, 1999; Mesquita, 2011).

Revista Brasileira de Políticas Públicas e Internacionais, v.4, n.1, julho/2019, pp. 29-47. 
MANSUR, Yasmine; CURSINO, Adélia Marina de Campos; TEODÓSIO, Armindo dos Santos de Souza. Programa de Atenção Integral à Saúde da Mulher: uma análise institucional

Pois bem, os estudos organizacionais nasceram das profundas transformações geradas pelo capitalismo industrial, quando se acreditava que a promessa iluminista da cientificidade e da racionalidade se materializava nas organizações modernas. No entanto, contemporaneamente, é notório que qualidade, racionalidade, eficiência, ética e objetividade não são virtudes inerentes às organizações (Reed, 2006). Tal constatação levou-nos a identificar no novo institucionalismo, formas e procedimentos utilizados pelas organizações modernas, que vão além de sua suposta motivação para a eficácia. O novo Institucionalismo nos ajuda a entender as organizações como práticas culturais, e por essa razão tão influenciadas pelos movimentos sociais (Hall \& Taylor, 2003). Refutando generalizações teóricas sobre o Estado, o neo-institucionalismo busca, através da descrição de casos concretos, demonstrar que diferentes processos históricos produzem padrões diferenciados de relação entre Estado e sociedade, relações essas que tornam-se mais complexas com a presença de novos atores, como é o caso do PAISM e da reforma sanitária (Taylor, 2003: Reed, 2006).

Como o novo institucionalismo, defende que para compreender a ação individual e coletiva é preciso analisar as mediações entre as estruturas sociais e os comportamentos individuais, ou seja, as "instituições" (Hall \& Taylor, 2003), observamos que a pressão exercida pelos movimentos sociais, evidência que as políticas públicas, podem sofrer influência dos diversos atores sociais - ou do Estado ou dos grupos de pressão da sociedade civil, por exemplo - em seus processos de elaboração.

Atento à fragmentação dos interesses na sociedade, o modelo neoinstitucionalista analisa a influência das instituições políticas sobre os grupos sociais e vice-versa, buscando contemplar análises de identidades, como gênero e raça, além de estratégias dos diversos atores sociais no processo de produção das políticas públicas, como aqui nos interessou observar a influência do movimento feminista na criação do PAISM, o que está em debate, portanto, é o poder e a autonomia das instituições estatais na definição de políticas públicas para a saúde da mulher, identificando o peso da influência da sociedade sobre o Estado e a ligação entre as políticas públicas e as complexas relações Estado-sociedade (Hall \& Taylor, 2003).

Outro aspecto direcionou este trabalho ao novo institucionalismo, em detrimento do velho, esse é a influência assumida, pelo novo institucionalismo, de fatores sociais como o

Revista Brasileira de Políticas Públicas e Internacionais, v.4, n.1, julho/2019, pp. 29-47. 
MANSUR, Yasmine; CURSINO, Adélia Marina de Campos; TEODÓSIO, Armindo dos Santos de Souza. Programa de Atenção Integral à Saúde da Mulher: uma análise institucional

confronto de interesses, o embate político-eleitoral e as transformações na esfera do poder como capazes de gerar mudanças profundas no setor de políticas públicas, fazendo surgir novos paradigmas. Ou seja, além de novos instrumentos e metas para a implementação de políticas, surgem novas ideias, como as do movimento feminista, e padrões que orientam a abordagem da realidade pelos especialistas. Os grupos de interesse vão fazer a ligação entre Estado e sociedade, as ideias assumem então um papel central na elaboração das políticas, legitimando alguns interesses em detrimento de outros, daí a importância do movimento feminista para implementação do PAISM.

Segundo DiMaggio \& Powell (1991) o neo-institucionalismo sociológico seria o conceito que melhor caracteriza o processo de homogeneização da conduta das organizações. Assim, todo esse processo de descentralização de políticas de saúde, sumarizadas no PAISM, podem ser compreendidas pelo isomorfismo institucional mimético que considera o comportamento do governo como uma resposta às incertezas em relação ao comportamento dos movimentos sociais, no caso o feminista e sanitarista, que exigiam a melhoria dos serviços públicos.

\section{Considerações Finais}

Pensar nos direitos das mulheres e dentro eles o direito à saúde, implica redefinir o que se entende por mulher e por direito a saúde, assim o PAISM constituiu um instrumento para inserir a questão da atenção à saúde da mulher levando-se em conta não apenas as questões médicas stricto sensu, mas sobretudo contextualizando a construção da saúde feminina a partir das relações sociais, culturais, políticas e econômicas que envolvem a realidade das mulheres brasileiras.

Visto que o presente artigo teve a intenção de lançar luz sobre a implementação do PAISM, observando que o movimento feminista aliado ao contexto de redemocratização exerceu grande influência sobre o Estado no que diz respeito a importância de políticas públicas especificas para as mulheres, foi importante entender como essa dinâmica incidiu sobre a constituição desse programa de políticas públicas. Para tanto, construímos um

Revista Brasileira de Políticas Públicas e Internacionais, v.4, n.1, julho/2019, pp. 29-47. 
MANSUR, Yasmine; CURSINO, Adélia Marina de Campos; TEODÓSIO, Armindo dos Santos de Souza. Programa de Atenção Integral à Saúde da Mulher: uma análise institucional

panorama, fundamentado nas teorias institucionais com um foco no novo institucionalismo, além de um resgate da trajetória histórica do movimento feminista.

Dada a construção deste panorama e ao analisar o cenário a época da criação do PAISM sob o viés do novo institucionalismo, e ciente de que as teorias institucionais buscam identificar microcenários de ação sem desconsiderar as dimensões estruturais da organização, pode-se constatar a relevância de se operar análises acerca de políticas públicas a partir dos marcos teórico-conceituais do novo institucionalismo. Ao privilegiar a dimensão simbólica das instituições e as dimensões da vida cotidiana das organizações, essa perspectiva teórica permitiu problematizar o PAISM à luz da trajetória de lutas, revezes e conquistas de direitos por parte do movimento feminista.

A análise da trajetória das lutas por direitos desenvolvidas pelo movimento feminista ao longo de sua trajetória permitiu perceber as interações, embates, tentativas de mudança de perspectiva compreensiva da realidade das mulheres, e os conflitos e conquistas, que operam nos interstícios da realidade material e subjetiva, das políticas instituídas e do simbolismo que reconfigura a operação dessa política.

Espera-se que a partir do presente trabalho novas investigações possam avançar na análise do papel dos movimentos sociais, sobretudo o movimento feminista, sobre as políticas públicas de saúde, utilizando para tal os marcos do novo institucionalismo. Com esse suporte teórico, que lança grande destaque aos aspectos simbólicos das interações entre organizações e sua influência na reprodução de suas políticas, pode-se avançar para além de visões e análises meramente formalistas das políticas públicas, destacando-se as idas, vindas e trajetórias que as lutas por direitos assumem ao se materializarem em políticas públicas. Pesquisas pautadas nesses princípios teóricos e analíticos podem lançar importantes perspectivas compreensivas sobre as interações entre Estado e movimento sociais na configuração de políticas públicas, trazendo mais avanços à incorporação de atores não governamentais e das lutas por direitos nas análises empreendidas no campo dos estudos da gestão social.

\section{Referências}

Andrade, J. A. (2006, maio/agosto). Redes De Atores: Uma Nova Forma De Gestão Das Políticas Públicas No Brasil? Gestão \& Regionalidade, 64.

Revista Brasileira de Políticas Públicas e Internacionais, v.4, n.1, julho/2019, pp. 29-47. 
MANSUR, Yasmine; CURSINO, Adélia Marina de Campos; TEODÓSIO, Armindo dos Santos de Souza. Programa de Atenção Integral à Saúde da Mulher: uma análise institucional

Amorim, L.T. (2011, agosto). Gênero: Uma Construção Do Movimento Feminista? Anais II Simpósio Gênero e Políticas Públicas, Universidade Estadual de Londrina, PR, Brasil.

Arretche, M. (1996), Mitos Da Descentralização: Mais Democracia E Eficiência Nas Políticas Públicas. Revista Brasileira De Ciências Sociais, 31 (11), 44-66. (Org.) (2004). O Associativismo Em São Paulo. São Paulo: Editora Da Unesp.

Berger, P. \& Luckmann, T. (2008). A Construção Social Da Realidade. Petrópolis, Vozes.

Bruschini, C. (2007, setembro/dezembro). Trabalho e gênero no Brasil nos últimos dez anos. Cadernos de Pesquisa, São Paulo, 37 (132), 537-572.

Cavalcante, P. (2011, novembro/dezembro). Descentralização De Políticas Públicas Sob A Ótica Neo Institucional: Uma Revisão De Literatura. Revista De Administração Pública, Rio De Janeiro (45) 6, 1781-1804.

Carvalho, C. A., Goulart, S., \& Vieira, M. M. F. (1999). A Inflexão Conservadora Na Trajetória Histórica Da Teoria Institucional. Anais do encontro Anual Da Associação Nacional Dos Programas De Pós-Graduação Em Administração, 28, Curitiba, PR, Brasil.

Chies, P. V. (2010, maio/agosto) Identidade De Gênero E Identidade Profissional No Campo De Trabalho. Estudos Feministas, Florianópolis, 18 (2), 507-528.

Costa, A. M. (1999). Desenvolvimento e Implantação do Paism no Brasil. In Giffin, K., \& Costa, S. H. (Orgs). Questões Da Saúde Reprodutiva. Rio De Janeiro: Ed. Fiocruz.

Descarries, F. (2000). Teorias Feministas: Liberação e Solidariedade no Plural. Textos De História Feminismo Teorias E Perspectivas (UNB), Brasília 8 (1/2).

Devreux A. M. (2009). Família. In Saboia, V. A. (Trad.) Hirata, H., Laborie, F., Le Doaré, H., \& Senotier, D. (Org.). Dicionário Crítico do Feminismo (pp. 96-101). São Paulo: Editora Unesp.

Dimaggio, P. J.; Powell, W. W. (2005). A Gaiola De Ferro Revisitada: Isomorfismo Institucional E Racionalidade Coletiva Nos Campos Organizacionais. Revista De Administração De Empresas, 45 (2), 74-89.

Escorel, S. (1998). Reviravolta Na Saúde. Origem e Articulação do Movimento Sanitário. Rio De Janeiro: Editora Fiocruz.

Farah, M. F. S. (2004, janeiro/abril) Gênero e Políticas Públicas. Estudos Feministas, Florianópolis, 12 (1), 47-71.

Revista Brasileira de Políticas Públicas e Internacionais, v.4, n.1, julho/2019, pp. 29-47. 
MANSUR, Yasmine; CURSINO, Adélia Marina de Campos; TEODÓSIO, Armindo dos Santos de Souza. Programa de Atenção Integral à Saúde da Mulher: uma análise institucional

Fleury, S. (1999). Políticas Sociales Y Ciudadanía. Indes/Bed: Washington.

Fonseca, V. S. (2003). Abordagem Institucional Nos Estudos Organizacionais: Bases Conceituais e Desenvolvimentos Contemporâneos. In: Vieira, M. M. F.; Carvalho, C. A. (Orgs.). Organizações, Instituições E Poder No Brasil (pp. 47-66). Rio De Janeiro: FGV.

Fonseca Sobrinho, D. (1993) Estado E População: Uma História Do Planejamento Familiar No Brasil. Rio De Janeiro: Rosa Dos Tempos/Fnuap.

Fougeyrollas-Schwebel, D. (2009). Movimentos Feministas. In Saboia, V. A. (Trad.) Hirata, H., Laborie, F., Le Doaré, H., \& Senotier, D. (Org.). Dicionário Crítico do Feminismo (pp. 144-149). São Paulo: Editora Unesp.

Gohn, M. G. (2003). Movimentos Sociais No Início Do Século Xxi: Antigos E Novos Atores Sociais. Petrópolis/RJ: Vozes.

Hall, P. \& Taylor, R. C. R. (2003). As Três Versões Do Neo-Institucionalismo. Lua Nova, N $^{\circ}$ 58, 193-224.

Hjort-Madsen, K. (2006). Enterprise Architecture Implementation and Management: A Case Study On Interoperability. 39th Hawaii International Conference On System Sciences. Ieee Computer Society, Kauia, HI, Estados Unidos.

Jensen, M. E. \& Meckling, W. (1976). Theory Of The Firm: Managerial Behavior, Agency Cost, And Ownership Structure. Journal Os Financial Economics, 3, 305-360.

Juteau-Lee, D. (2009). Etnicidade e Nação. In Saboia, V. A. (Trad.) Hirata, H., Laborie, F., Le Doaré, H., \& Senotier, D. (Org.). Dicionário Crítico Do Feminismo. São Paulo: Unesp, 2009. pp. 90-96.

Lunardi, G. L. (2008). Um Estudo Empírico E Analítico Do Impacto Da Governança De Ti No Desempenho Organizacional. (Tese de Doutorado) Universidade Federal do Rio Grande do Sul, Programa de Pós-Graduação em Administração, Porto Alegre.

Machado-Da-Silva, C. L. \& Gonçalves, S. A. (1998). Nota Técnica; A Teoria Institucional. In: Clegg, S. R.; Hardy, C; Nord, W. Handbook De Estudos Organizacionais: Modelos De Análise E Novas Questões Em Estudos Organizacionais. Vol. 1. São Paulo: Atlas.

Mesquita, C. C. de (2011). Saúde Da Mulher E Redemocratização: Ideias e Atores Políticos Na História Do Programa De Assistência Integral À Saúde Da Mulher. Congresso Luso-AfroBrasileiro De Ciências Sociais. UFBA.

Revista Brasileira de Políticas Públicas e Internacionais, v.4, n.1, julho/2019, pp. 29-47. 
MANSUR, Yasmine; CURSINO, Adélia Marina de Campos; TEODÓSIO, Armindo dos Santos de Souza. Programa de Atenção Integral à Saúde da Mulher: uma análise institucional

Meyer, J. W. \& Rowan, B. (1977). Organizações Institucionalizadas: Estrutura Formal Como Mito Cerimónia. American Journal Of Sociology, 83 (2), 340-363.

Milani, C. R. S. (2008, maio/junho). O Princípio Da Participação Social Na Gestão De Políticas Públicas Locais: Uma Análise De Experiências Latino-Americanas E Europeias. Revista De Administração Pública, Rio de Janeiro, 42 (3), 551-79.

Miranda, C. M. (2009). Os Movimentos Feministas E A Construção De Espaços Institucionais Para A Garantia Dos Direitos Das Mulheres No Brasil. NIEM / UFRGS.

Oliveira, A. R. De; Gaio, L. E., \& Bonacim, C. A. G. (2009). Relações de gênero e ascensão feminina no ambiente organizacional: um ensaio teórico. Revista de Administração da UFSM, 2 (1), 80-97.

Pedro, C. B., Guedes, O. de S. (2010). As Conquistas Do Movimento Feminista Como Expressão Do Protagonismo Social Das Mulheres. Anais Do I Simpósio Sobre Estudos De Gênero E Políticas Públicas, Universidade Federal de Londrina, PR, Brasil.

Pinto, C. R. J. (2010, junho). Feminismo, História e Poder. Revista Sociologia Política, Curitiba, 18 (36), 15-23.

Prates, A. A. (2000). Organização e Instituição no Novo Institucionalismo, Teoria \& Sociedade, Belo Horizonte, 5, 123-146.

Reed, M. (2006). Teoria Organizacional: Um Campo Historicamente Contestado. In: Clegg, S., Hardy, C., \& Nord, W. Handbook De Estudos Organizacionais. $3^{\text {a }}$ Ed. São Paulo: Atlas.

Selznick, P. (1996, junho). Institutionalism "Old" And "New". Administrative Science Quarterly, 41 (2), 270-277.

Scott, W. R. (2001, dezembro). The Adolescence Of Institutional Theory. Administrative Science Quarterly, 32 (4), 493-511.

Tolbert, P. S. \& Zucker, L. G. (1998). A Institucionalização Da Teoria Institucional. In Clegg, S. R.; Hardy, C; Nord, W. Handbook De Estudos Organizacionais: Modelos De Análise E Novas Questões Em Estudos Organizacionais (pp.196-219). São Paulo: Atlas.

Vilas Boas, L.H. De B. et al (2003, jul./ago./set.). Relações De Gênero Nas Organizações: Um Estudo No Setor De Vendas De Veículos. Revista De Administração, São Paulo, 38 (3), 219229.

Wallerstein, N. (1994). Empowerment Education Applied To Youth. In: Mattiella, A.C. The Multicultural Challange In Heath Education. Santa Cruz (California): Etr Associates Publishers.

Revista Brasileira de Políticas Públicas e Internacionais, v.4, n.1, julho/2019, pp. 29-47. 